\title{
Lower Flexor Surface
}

National Cancer Institute

\section{Source}

National Cancer Institute. Lower Flexor Surface. NCI Thesaurus. Code C147162.

Pertaining to the lower portion of the surface on the same side of the joint when it bends. 